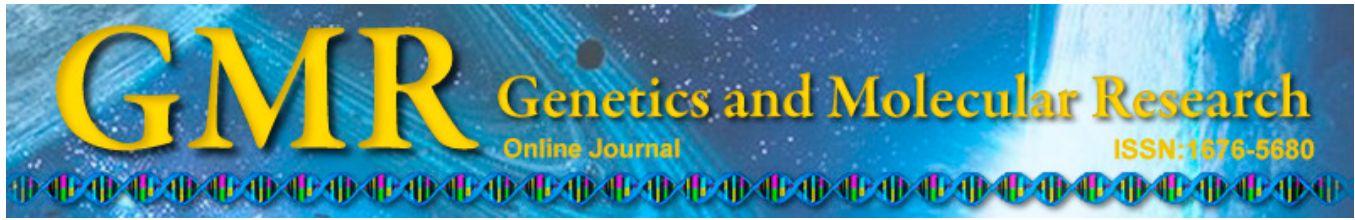

\title{
Physical localization of molecular markers and assignment of the 15 th linkage group to chromosome 11 of the karyotype in cassava (Manihot esculenta Crantz) by primed in situ labeling
}

\author{
Y. Wang*, J.F. Wang*, H. Yin, H.Q. Gao, N.S. Zhuang and J.P. Liu \\ Hainan Key Laboratory for Sustainable Utilization of Tropical Bioresources, \\ College of Agronomy, Hainan University, Haikou, Hainan Province, China \\ *These authors contributed equally to this study. \\ Corresponding author: J.P. Liu \\ E-mail: liu3305602@163.com
}

Genet. Mol. Res. 14 (3): 8366-8374 (2015)

Received November 3, 2014

Accepted March 18, 2015

Published July 28, 2015

DOI http://dx.doi.org/10.4238/2015.July.28.3

\begin{abstract}
Physical localization of molecular markers and assignment of the 15th linkage group to chromosome 11 of the karyotype in cassava (Manihot esculenta Crantz) were achieved using primed in situ labeling. Amplified signals for both the EST507-1 and SSRY13-5 markers were consistently observed in different stages of cell division. A comparison of the length, arm ratio, and other morphological characteristics of somatic metaphase chromosomes in karyotype analysis indicated that the EST507-1 and SSRY13-5 markers were localized on the short and long arm of cassava chromosome 11 with the relative map positions of 41.67 and 23.07, respectively. The physical localization of the 2 markers on chromosome 11 of the karyotype corresponds to their positions on the 15th linkage group in cassava.
\end{abstract}

Key words: Cassava; Linkage group; Manihot esculenta;

Molecular genetic map; Primed in situ labeling; Physical localization 


\section{INTRODUCTION}

Integrated linkage and physical genome maps are tremendously useful for genome sequencing projects, map-based gene isolation, and comparative genome research (Klein et al., 2000; Islam-Faridi et al., 2002). The assignment of linkage groups to specific chromosomes will allow for accurate and detailed integration of cytogenetic and genetic linkage maps. Fluorescence in situ hybridization (FISH) has been conventionally used to integrate genetic and chromosomal maps in several plant species (Jiang et al., 1995; Dong et al., 2000; Sadder et al., 2000; Cheng et al., 2001a,b; Kulikova et al., 2001; Howell et al., 2002; Islam-Faridi et al., 2002; Kim et al., 2002; Pedrosa et al., 2002; Koumbaris and Bass, 2003; Zhang et al., 2005; Wang et al., 2008). Because of the combination of accuracy and sensitivity of polymerase chain reaction (PCR) with FISH, primed in situ labeling (PRINS) has been found to be a more powerful tool for localizing DNA sequences, single-copy genes (Macas et al., 2000; Kubaláková et al., 2001; Tatum and Rayburn, 2006; Kaczmarek et al., 2007; Gao et al., 2011), and restriction fragment length polymorphism loci (Zhu et al., 1995; Shi et al., 1996) in some plants (Birchler and Danilova, 2012).

Cassava (Manihot esculenta Crantz) is an important tuber crop extensively planted in tropical and subtropical regions (Alves, 2001; Jennings and Iglesias, 2001). As a dicotyledonous plant in Euphorbiaceae, cassava has an allopolyploid genome with 36 chromosomes in somatic cells $(2 \mathrm{~N}=36)$, and its haploid genome is estimated to be approximately $772 \mathrm{Mbp}$ long (Bennett et al., 1982; Awoleye et al., 1994). A number of molecular marker-based genetic linkage maps have been constructed (Fregene et al., 1997; Mba et al., 2001; Okogbenin et al., 2006; Kunkeaw et al., 2010a,b; Chen et al., 2010; Sraphet et al., 2011). A draft genome sequence of a single cassava accession is also available (Prochnik et al., 2012). Despite significant advances in molecular methods, few studies have examined the molecular cytogenetics of cassava and the genetic linkage groups obtained by different researchers have not been integrated into individual chromosomes. In previous studies, we successfully assigned a linkage group to a member of the cassava karyotype (Wang et al., 2013). Here, we report physical locations of molecular markers and assignment of the 15th linkage group to chromosome 11 of the karyotype in cassava (M. esculenta Crantz) using PRINS.

\section{MATERIAL AND METHODS}

\section{Plant materials}

A cassava variety South No. 6 (SC6), provided by Tropical Crops Genetic Resources Institute, Chinese Academy of Tropical Agriculture, was used as experimental material.

\section{Chromosome preparation}

The method described by Wang et al. (2012) was used with some modifications. Root tips with lengths of approximately $1 \mathrm{~cm}$ were harvested and pretreated in $0.002 \mathrm{M} 8$-hydroxyquinoline for $2 \mathrm{~h}$. They were then washed with double-distilled water, fixed in fresh Carnoy's solution (ethanol:glacial acetic acid, 3:1) for $18-24 \mathrm{~h}$ at $4^{\circ} \mathrm{C}$, rinsed in double-distilled water for $30 \mathrm{~min}$, and placed in an enzyme solution of $3.5 \%$ cellulose and $1.75 \%$ pectinase for $4-5 \mathrm{~h}$ at $37^{\circ} \mathrm{C}$. The root tips were rinsed, subjected to hypotonic treatment for $30 \mathrm{~min}$ again 
with double-distilled water, and fixed for 20-30 min. Metaphase chromosomes were placed on poly-L-lysine-coated glass slides using the flame drying technique. The slides were air-dried and stained with 5\% Giemsa solution, $\mathrm{pH} 7.0$, for 20-25 min.

\section{PRINS reaction}

Using a modified method described by Gao (2012), 2 molecular markers, EST507-1 and SSRY13-5 of the 15th linkage group (LG15) map published by Chen et al. (2010), were physically located. Two pairs of primers were used, with sequences for the 2 markers as follows: 5'-GGAATGAGTCCGAATATGAA-3' (upstream primer) and 5'-ATATTTCTTGCGGC TATGAC-3' (downstream primer) for EST507-1, 5'-GCAAGAATTCCACCAGGAAG-3' (upstream primer) and 5'-CAATGATGGTAAGATGGTGCAG-3' (downstream primer).

Slides were immersed in $0.01 \mathrm{M} \mathrm{HCl}$ for $10 \mathrm{~min}$, incubated in $50 \mu \mathrm{L} 1 \mu \mathrm{g} / \mathrm{mL}$ pepsin and $0.01 \mathrm{M} \mathrm{HCl}$ at $37^{\circ} \mathrm{C}$ for $10 \mathrm{~min}$, washed with $0.5 \mathrm{X}$ Tris-buffered saline solution for 10 min, rinsed with sterilized distilled water for 5 min twice, and then air-dried.

The slides were denatured for $5 \mathrm{~min}$ at $70^{\circ} \mathrm{C}$ in $70 \%$ formamide/ $0.1 \mathrm{X}$ standard saline citrate (SSC), $\mathrm{pH} 7.0$, and immediately immersed in 0.1X SSC in an ice water bath for $1 \mathrm{~min}$ and then rinsed with sterile water in an ice water bath for $1 \mathrm{~min}$. Subsequently, slides were dehydrated in an ethanol series $(75,90$, and $100 \%)$ at $-20^{\circ} \mathrm{C}$ for 3 min each and were allowed to air dry.

To each slide, we added $50 \mu \mathrm{L}$ labeling reaction mixture and then sealed the slide with $20 \mu \mathrm{L}$ mineral oil. The labeling reaction mixture contained $5 \mathrm{X}$ buffer, $25 \mathrm{mM} \mathrm{MgCl}, 10 \mathrm{mM}$ dATP, $10 \mathrm{mM}$ dGTP, $10 \mathrm{mM}$ dCTP, $3.6 \mathrm{mM}$ dTTP, 20 mM DIG-11-dUTP, 5 U Taq DNA polymerase, $20 \mathrm{mM}$ F-primers, $20 \mathrm{mM}$ R-primers, and $6 \mu \mathrm{L}$ double-distilled $\mathrm{H}_{2} \mathrm{O}$. Slides without Taq DNA polymerase or primers were used as negative controls in this study. Chromosomal DNA was first denatured for $10 \mathrm{~min}$ at $95^{\circ} \mathrm{C}$. The reactions were then thermocycled 35 times $\left(1 \mathrm{~min}\right.$ at $94^{\circ} \mathrm{C}, 1 \mathrm{~min}$ at $55^{\circ} \mathrm{C}, 2 \mathrm{~min}$ at $72^{\circ} \mathrm{C}$ ) and the reaction was terminated with a final extension at $72^{\circ} \mathrm{C}$ for $10 \mathrm{~min}$.

\section{Signal detection and localization}

After amplification, the coverslips were removed and slides were washed with $0.1 \mathrm{X}$ phosphate-buffered saline at $37^{\circ} \mathrm{C}$ for $5 \mathrm{~min}$. The slides were placed in $100 \mu \mathrm{L} 5 \%$ bovine serum albumin ( $0.1 \mathrm{X} \mathrm{SSC/Tween} 20)$ and then covered with plastic coverslips and incubated at $37^{\circ} \mathrm{C}$ for $20 \mathrm{~min}$. Next, the slides were incubated in $50 \mu \mathrm{L} 20 \mathrm{mg} / \mathrm{L}$ anti-DIG-fluorescein with plastic coverslips at $37^{\circ} \mathrm{C}$ for $1 \mathrm{~h}$, and followed by multiple washes in $0.1 \mathrm{X} \mathrm{SSC} /$ Tween 20 for $5 \mathrm{~min}$. The slides were counterstained with $1 \mu \mathrm{g} / \mathrm{mL}$ propidium iodide for $30 \mathrm{~min}$ in the dark at $4^{\circ} \mathrm{C}$; the total volume was $25 \mu \mathrm{L}$. Observations were made using a fluorescent microscope (BX51TR-32Fa1-A03, Olympus, Tokyo, Japan) and photos were acquired using a DP72 Microscope Digital Photograph Camera attached to the microscope. The positions of amplification signal of molecular markers were analyzed based on relative map position and the percentage of the distance (in $\mu \mathrm{m}$ ) from the signal site to the centromere relative to the length of the chromosome arm (in $\mu \mathrm{m})$. Relative map position was calculated based on the average value of that measured in at least 5 individual cells. 


\section{RESULTS}

\section{Physical location of EST507-1 in the 15th linkage group of cassava}

PRINS studies using the EST507-1 primers revealed the presence of the EST507-1 marker on chromosome 11. The yellow-green fluorescent signal was detected in the nuclei during different phase of cell division but the signal was absent in the negative control (Figure 1). Karyotype analysis showed that EST507-1 was located on the short arm of chromosome 11 (Figure 2).
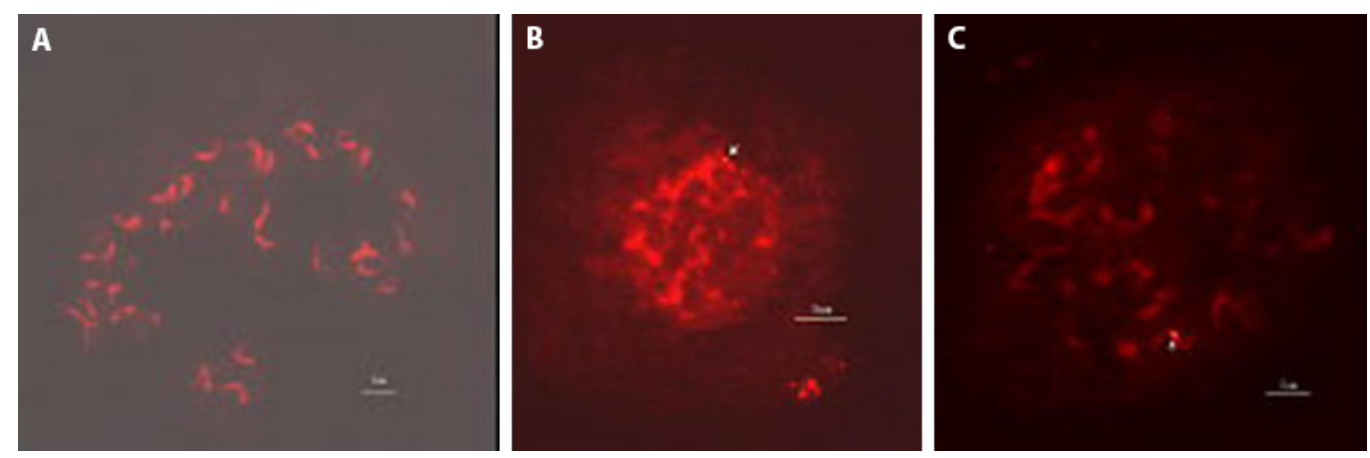

Figure 1. EST507-1 signal in cassava interphase and prometaphase nuclei. A. Negative control. B. Interphase nucleus. C. Prometaphase nucleus. Arrows for the yellow-green fluorescent signal of EST507-1. Scale bar $=5 \mu \mathrm{m}$.

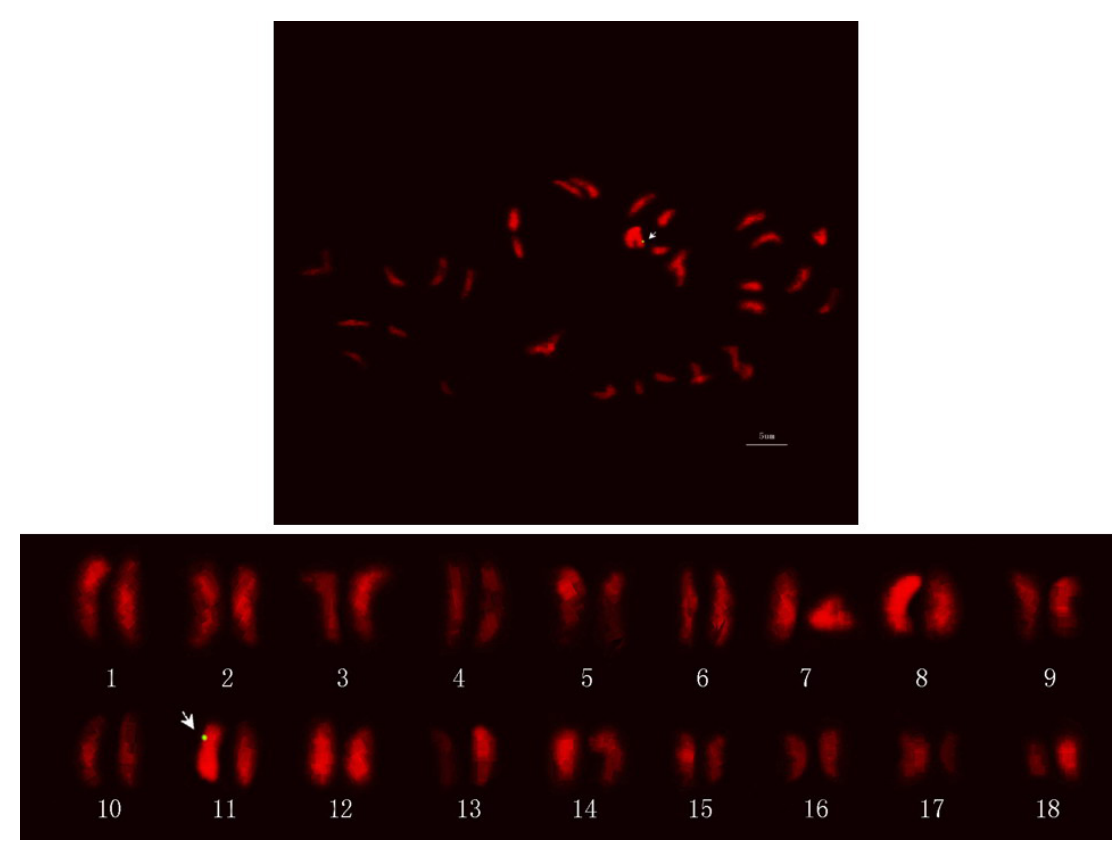

Figure 2. EST507-1 signal on cassava metaphase chromosome 11. Arrows for the yellow-green fluorescent signal of EST507-1. Scale bar $=5 \mu \mathrm{m}$. 


\section{Physical location results of SSRY13-5 in the 15th linkage group of cassava}

PRINS labeling showed that the signal for SSRY13-5 was successfully detected in both interphase and prometaphase nuclei but not in the negative control (Figure 3). Karyotype analysis demonstrated that SSRY13-5 was amplified on the long arm of chromosome 11 by PRINS (Figure 4).
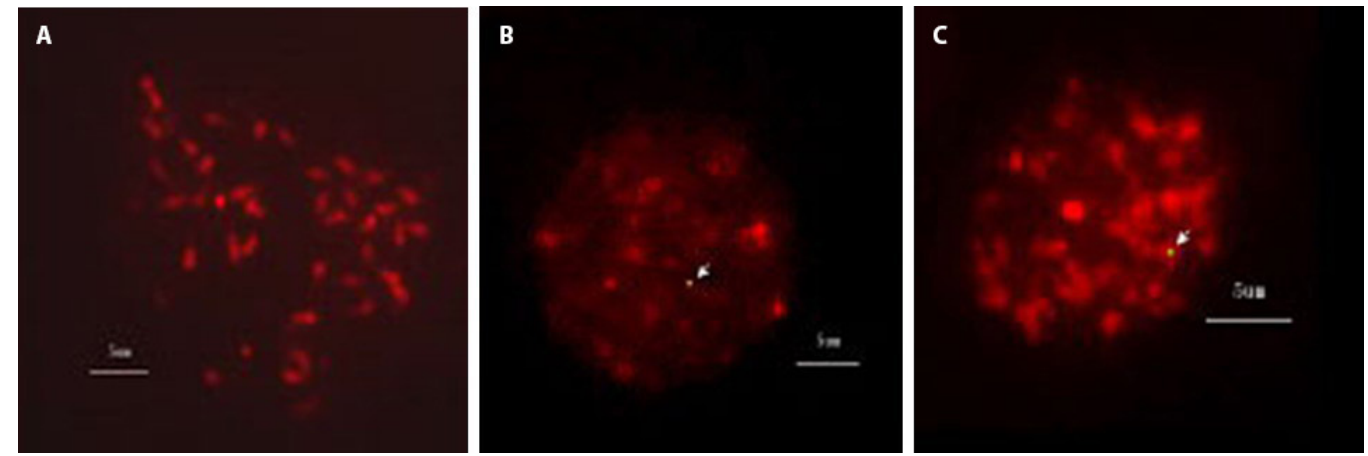

Figure 3. SSRY13-5 signal in cassava interphase and prometaphase nuclei. A. Negative control. B. Interphase nucleus. C. Prometaphase nucleus. Arrows for the yellow-green fluorescent signal of SSRY13-5. Scale bar $=5 \mu \mathrm{m}$.

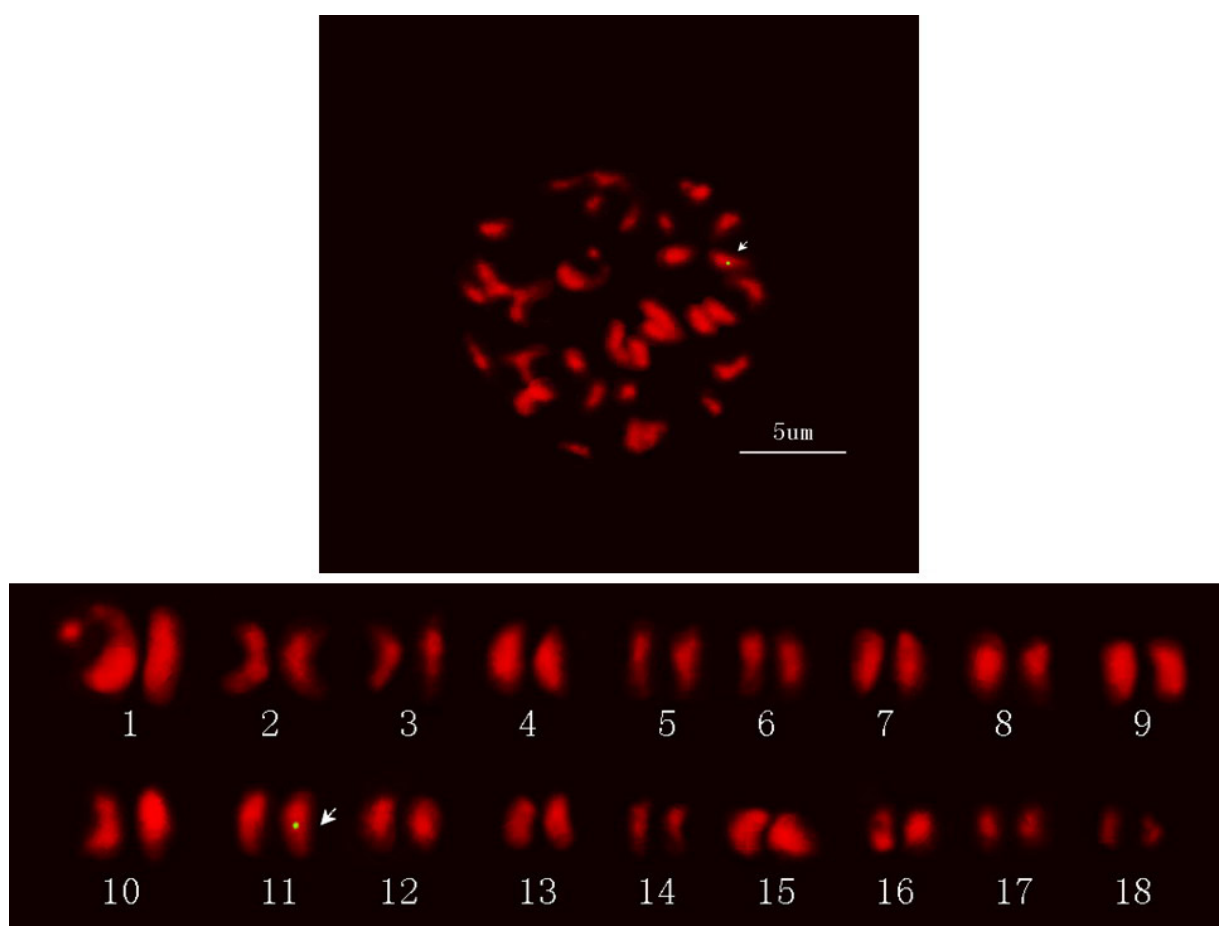

Figure 4. SSRY13-5 signal on cassava metaphase chromosome 11. Arrows for the yellow-green fluorescent signal of SSRY13-5. Scale bar $=5 \mu \mathrm{m}$. 


\section{Assignment of the 15th linkage group to chromosome 11 of the karyotype in cassava}

Based on the length, arm ratio, and other morphological characteristics of somatic metaphase chromosomes, a standardized karyotype (ideogram) (Figure 5) for cassava was established, allowing us to distinguish individual chromosomes. Karyotype analysis and comparison of the chromosomes physically mapped with 2 molecular markers showed that the EST507-1 and SSRY13-5 markers were located on the short and long arms of cassava chromosome 11 with relative map positions of 41.67 and 23.07 (Figures 5 and 6), respectively. Both the EST507-1 and SSRY13-5 markers were mapped to the 15th linkage group constructed by Chen et al. (2010). Therefore, the 15th linkage group can be assigned and integrated to chromosome 11 of the karyotype in cassava.

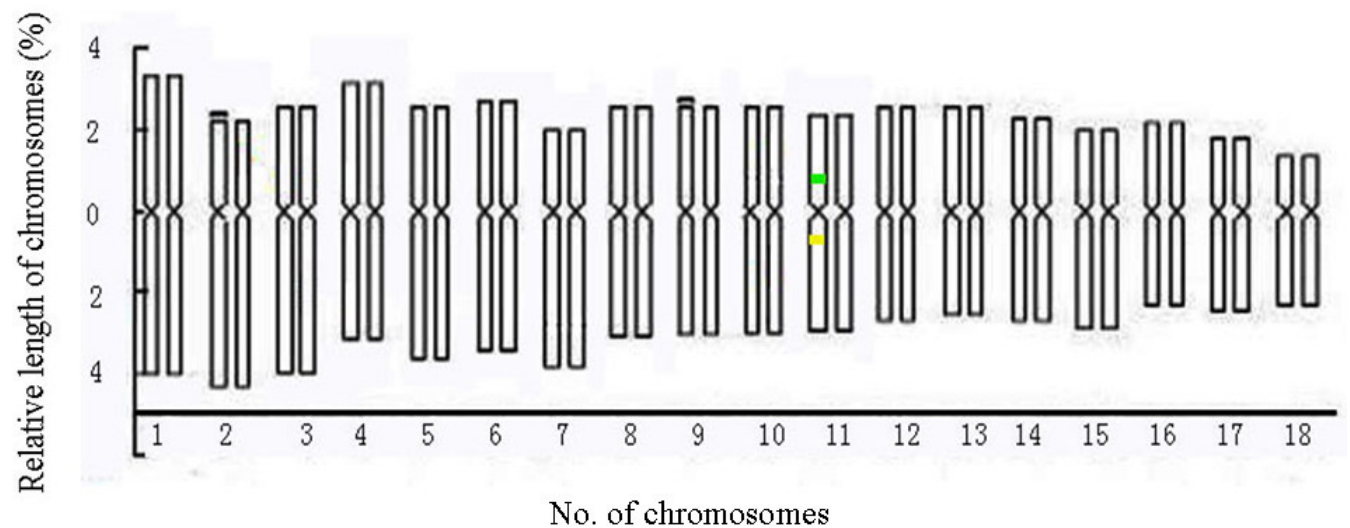

Figure 5. Idiogram of cassava metaphase chromosomes.

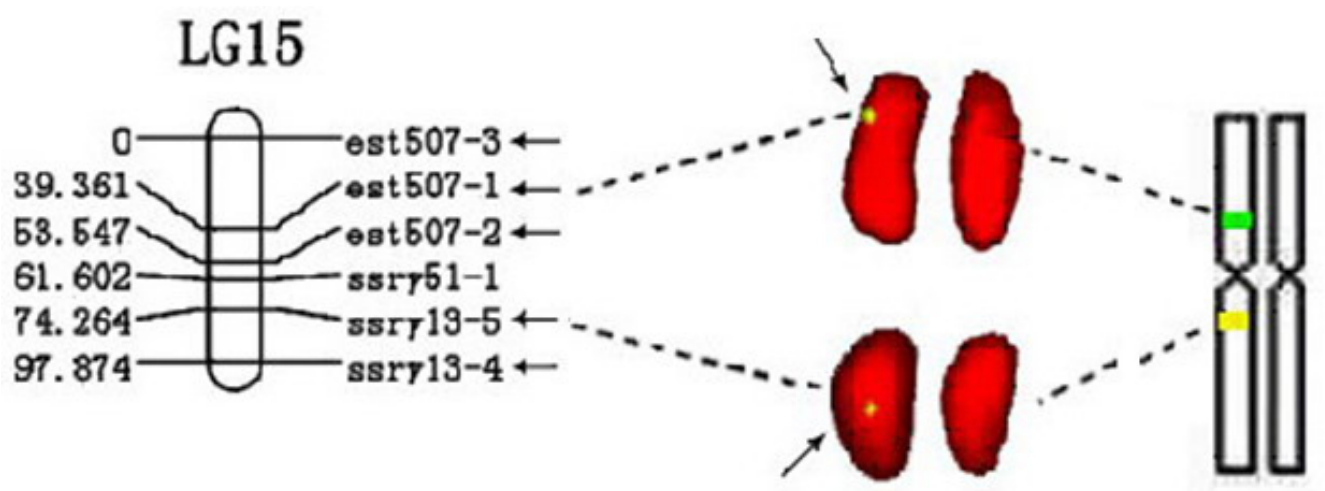

Figure 6. Comparison of the 15 th linkage group (left), labeled metaphase chromosome 11 (middle) and the diagram chromosome 11 (right) of cassava. Arrows denote amplified signals.

\section{DISCUSSION}

The assignment and integration of linkage maps to individual chromosomes of the karyotype of cassava is very useful for gene cloning and genomic investigations. PRINS 
can be used to detect relatively small chromosomal regions, DNA sequences, and molecular marker loci that cannot be observed using the FISH technique (Zhu et al., 1995; Shi et al., 1996; Macas et al., 2000; Kubaláková et al., 2001; Tatum and Rayburn, 2006; Kaczmarek et al., 2007). In this study, we demonstrated the feasibility of determining the physical location of molecular markers and assigning a linkage group to an individual chromosome of the karyotype in cassava using 2 markers by PRINS. The physical location of the 2 markers on chromosome 11 of the karyotype was consistent with their positions on the 15th linkage group.

We found that using poly-L-lysine-coated glass slides was critical for preventing the dropping of target cells and for improving the efficiency of in situ PCR amplification, and $0.1 \mathrm{X}$ phosphate-buffered saline solution washing for $5 \mathrm{~min}$ at $37^{\circ} \mathrm{C}$ was necessary to obtain a clean background and to obtain stronger signals. Furthermore, the steady occurrence of amplified signals in different stages of cell division ensured the authenticity of the signals.

It should be also noted that pachytene chromosomes are uniform in chromosome packaging and condensation, and are generally longer than somatic metaphase chromosomes (McClintock, 1929; Ramanna and Prakken, 1967; Peterson et al., 1999), and thus it would be advantageous to use 2-color or multicolor simultaneous mapping techniques and pachytene chromosome spreads as they allow for precise and fine-resolution physical mapping. Our results can be applied to study the molecular cytogenetics of cassava.

\section{ACKNOWLEDGMENTS}

Research financially supported by the Hainan Province Major Science and Technology Project (\#ZDZX2013023), the Western Plan and Subject Key Areas Construction Project of Hainan University (\#ZXBJH-XK001), National Basic Research Program (“973” Program) of China (\#2010CB1266060), the National Science Foundation of Hainan Province (\#313040), and the Research Funds for Hainan Universities (\#kyqd1409).

\section{REFERENCES}

Alves AGC (2001). Cassava botany and physiology. In: Cassava: biology, production and utilization (Hillocks RJ, Thresh JM and Bellotti AC, eds.). CABI, Wallingford, 67-90.

Awoleye F, Duren M, Dolezel J and Novak FJ (1994). Nuclear DNA content and in vitro induced somatic polyploidization cassava (Manihot esculenta Crantz) breeding. Euphytica 76: 195-202.

Bennett MD, Smith JB and Heslop-Harrison JS (1982). Nuclear DNA amounts in angiosperms. Proc. R. Soc. Lond. Ser. B. Biol. Sci. 274: 179-199.

Birchler JA and Danilova TV (2012). Chapter 13 Fluorescence in situ hybridization and in situ PCR. In: Plant Genetics and Genomics: Crops and Models, Vol. 4. Plant Cytogenetics: Genome Structure and Chromosome Function (Bass HW and Birchler JA, eds.). Springer, New York, 295-309.

Chen X, Xia Z, Fu Y, Lu C, et al. (2010). Constructing a genetic linkage map using an F1 population of non-inbred parents in cassava (Manihot esculenta Crantz). Plant Mol. Biol. Report. 28: 676-683.

Cheng ZK, Buell CR, Wing RA, Gu M, et al. (2001a). Toward a cytological characterization of the rice genome. Genome Res. 11: 2133-2141.

Cheng ZK, Presting GG, Buell CR, Wing RA, et al. (2001b). High-resolution pachytene chromosome mapping of bacterial artificial chromosomes anchored by genetic markers reveals the centromere location and the distribution of genetic recombination along chromosome 10 of rice. Genetics 157: 1749-1757.

Dong F, Song J, Naess SK, Helgeson JP, et al. (2000). Development and applications of a set of chromosome-specific cytogenetic DNA markers in potato. Theor. Appl. Genet. 101: 1001-1007.

Fregene M, Angel F, Gomez R, Rodriguez F, et al. (1997). A molecular genetic map of cassava (Manihot esculenta Crantz). Theor. Appl. Genet. 95: 431-441. 
Gao HQ (2012) Chromosome locations of HbMybl gene from Hevea brasiliensis by in situ PCR. J. Trop. Subtrop. Bot. 20: 365-368 (in Chinese with English abstract).

Gao JL, Nie Y and Ding XP (2011). Primed in situ labeling for detecting single-copy genes. Genet. Mol. Res. 10: 1884-1890.

Howell EC, Barker GC, Jones GH, Kearsey MJ, et al. (2002). Integration of the cytogenetic and genetic linkage maps of Brassica oleracea. Genetics 161: 1225-1234.

Islam-Faridi MN, Childs KL, Klein PE, Hodnett G, et al. (2002). A molecular cytogenetic map of sorghum of chromosome 1: fluorescence in situ hybridization analysis with mapped bacterial artificial chromosomes. Genetics 161: 345-353.

Jennings DL and Iglesias C (2001). Breeding for crop improvement. In: Cassava biology, production and utilization. (Hillocks RJ, Thresh JM and Bellotti AC, eds.) CABI/Embrapa, Wallingford, 149-165.

Jiang J, Gill BS, Wang GL, Ronald PC, et al. (1995). Metaphase and interphase fluorescence in situ hybridization mapping of the rice genome with bacterial artificial chromosomes. Proc. Natl. Acad. Sci. U. S. A. 92: 4487-4491.

Kaczmarek A, Naganowska B and Wolko B (2007). PRINS and C-PRINS: promising tools for the physical mapping of the lupin genome. Cell Mol. Biol. Lett. 12: 16-24.

Kim J-S, Childs KL, Islam-Faridi MN, Menz MA, et al. (2002). Integrated karyotyping of sorghum by in situ hybridization of landed BACs. Genome 45: 402-412.

Klein PE, Klein RR, Cartinhour SW, Ulanch PE, et al. (2000). A high-throughput AFLP-based method for constructing integrated genetic and physical maps: progress toward a sorghum genome map. Genome Res. 10: 789-809.

Koumbaris GL and Bass HW (2003). A new single-locus cytogenetic mapping system for maize (Zea mays L.): overcoming FISH detection limits with marker-selected sorghum (S. propinquum L.) BAC clones. Plant J. 35: 647-659.

Kubaláková M, Vrána J, Č́halíková J, Lysák MA, et al. (2001). Localisation of DNA sequences on plant chromosomes using PRINS and C-PRINS. Methods Cell Sci. 23: 71-82.

Kulikova O, Gualtieri G, Geurts R, Kim DJ, et al. (2001). Integration of the FISH pachytene and genetic maps of Medicago truncatula. Plant J. 27: 49-58.

Kunkeaw S, Tangphatsornruang S, Smith DR and Triwitayakorn K (2010a). Genetic linkage map of cassava (Manihot esculenta Crantz) based on AFLP and SSR markers. Plant Breed. 129: 112-115.

Kunkeaw S, Yoocha T, Sraphet S, Boonchanawiwat A, et al. (2010b). Construction of a genetic linkage map using simple sequence repeat markers from expressed sequence tags for cassava (Manihot esculenta Crantz). Mol. Breed. 27: 67-75.

Macas J, Požárková D, Navrátilová A, Nouzová M, et al. (2000). Two new families of tandem repeats isolated from genus Vicia using genomic self-priming PCR. Mol. Gen. Genet. 263: 741-751.

Mba REC, Stephenson P, Edwards K, Melzer S, et al. (2001). Simple sequence repeat (SSR) markers survey of the cassava (Manihot esculenta Crantz) genome: towards an SSR-based molecular genetic map of cassava. Theor. Appl. Genet. 102: 21-31.

McClintock B (1929). Chromosome morphology in Zea mays. Science 69: 629-630.

Okogbenin E, Marin J and Fregene M (2006). An SSR-based molecular genetic map of cassava. Euphytica 147: 433-440.

Pedrosa A, Sandal N, Stougaard J, Schweizer D, et al. (2002). Chromosomal map of the model legume Lotus japonicus. Genetics 161: 1661-1672.

Peterson DG, Lapitan NLV and Stack SM (1999). Localization of single- and low-copy sequences on tomato synaptonemal complex spreads using fluorescence in situ hybridization (FISH). Genetics 152: 427-439.

Prochnik S, Marri PR, Desany B, Rabinowicz PD, et al. (2012). The Cassava Genome: Current Progress, Future Directions. Tropical Plant Biol. 5: 88-94.

Ramanna MS and Prakken R (1967). Structure of and homology between pachytene and somatic metaphase chromosomes of tomato. Genetica 38: 115-133.

Sadder MT, Ponelies N, Born U and Weber G (2000). Physical localization of single-copy sequences on pachytene chromosomes in maize (Zea mays L.) by chromosome in situ suppression hybridization. Genome 43: 1081-1083.

Shi L, Zhu T, Morgante M, Rafalski JA, et al. (1996). Soybean chromosome painting: a strategy for somatic cytogenetics. J. Hered. 87: 308-313.

Sraphet S, Boonchanawiwat A, Thanyasiriwat T, Boonseng O, et al. (2011). SSR and EST-SSR-based genetic linkage map of cassava (Manihot esculenta Crantz). Theor. Appl. Genet. 122: 1161-1170.

Tatum TC and Rayburn AL (2006). PRINS-labeled knobs are not associated with increased chromosomal stickiness in the maize st1 mutant. J. Hered. 97: 417-422.

Wang C, Wang JF, Zhuang NS and Wang Y (2012). Optimization of chromosome spreading technique in cassava root tip cells. Chin. J. Trop. Crops 33: 627-630 (in Chinese with English abstract).

Wang JF, Gao HQ, Zhuang NS, Li KM, et al. (2013). The integration of sixteenth linkage group of genetic and cytological maps in cassava. Chin. J. Trop. Crops 20: 1018-1023 (in Chinese with English abstract).

Wang K, Guan B, Guo WZ, Zhou B, et al. (2008). Completely distinguishing individual A-genome chromosomes and 
their karyotyping analysis by multiple bacterial artificial chromosome-fluorescence in situ hybridization. Genetics 178: 1117-1122.

Zhang DF, Yang QY, Bao W-D, Zhang Y, et al. (2005). Molecular cytogenetic characterization of the Antirrhinum majus genome. Genetics 169: 325-335.

Zhu T, Shi L and Keim P (1995). Detection by in situ fluorescence of short, single copy sequences of chromosomal DNA. Plant Mol. Biol. Rep. 13: 270-277. 